\title{
EDUCAÇÃO AMBIENTAL E AGROECOLOGIA: RELATO E ANÁLISE DE UM CURSO PARA AGRICULTOR(A) ORGÂNICO(A) E AGROECOLÓGICO(A)
}

\author{
Valéria Cristina da Costa ${ }^{1}$, Deliene Fracete Gutierrez ${ }^{1}$, \\ Ana Carolina da Costa Carvalho², Ivan Carlos Carreiro Almeida ${ }^{3}$, \\ Katia Maria da Silva ${ }^{1}$, Leonel de Oliveira Pinheiro ${ }^{1}$, Lucas Teixeira Ferrari ${ }^{3}$, \\ Luís Ricardo de Souza Corrêa ${ }^{1}$, Maíra Queiroz Rezende ${ }^{3}$, \\ Mayne Luísa Silva Veronesi ${ }^{1}$, Reinaldo Duque Brasil Landulfo Teixeira ${ }^{4}$, \\ Izabela Macedo Lima ${ }^{3}$
}

Resumo: Este artigo tem por objetivo relatar e analisar o processo de realização de um curso para Agricultor(a) Orgânico(a) e Agroecológico(a). O curso foi realizado em comunidades rurais, utilizando metodologias participativas e promovendo a troca de conhecimentos entre os saberes locais, técnicos e acadêmicos. Organizados em sete módulos, os temas foram escolhidos com a intenção de contribuir para a transição agroecológica no Vale do Mucuri (MG), considerando-se a realidade ambiental e produtiva desse território. $\mathrm{O}$ curso foi bem avaliado pelos participantes e contribuiu para a formação de uma rede de agricultores interessados na agroecologia como forma de produção de alimentos aliada à conservação ambiental.

Palavras-chave: Educação do Campo; Núcleo Mucuri de Agroecologia; Curso FIC; Sustentabilidade; Agricultura familiar.

\begin{abstract}
This article aims to report and analyse the process involved in holding a course on Organic and Agroecological Agriculture. It was held in rural communities, using participatory methodologies, fostering exchanges among local, technical, and academic knowledges. The course had seven modules, and the themes were chosen with intent of contributing to the agroecological transition in Mucuri Valley (MG, Brazil), as well as considering the environmental and productive reality of that territory. The course was well evaluated by participants, and it contributed to the formation of a network of farmers interested in agroecology as a form of food production combined with environmental conservation.
\end{abstract}

Keywords: Rural Education; Mucuri Center for Agroecology; FIC Course; Sustainability; Family Agriculture.

\footnotetext{
${ }^{1}$ Universidade Federal dos Vales do Jequitinhonha e Mucuri

2 Rede de Ensino Doctum

3 Instituto Federal do Norte de Minas Gerais

${ }^{4}$ Universidade Federal de Juiz de Fora
} 


\title{
Introdução
}

A Educação Ambiental, instituída pela Lei № 9.795/1999 e intitulada como Política Nacional de Educação Ambiental é constituída de "processos por meio dos quais o indivíduo e a coletividade constroem valores sociais, conhecimentos, habilidades, atitudes e competências voltadas para a conservação do meio ambiente" (BRASIL, 1999). Ainda de acordo com essa lei, trata-se de "um componente essencial e permanente da educação nacional, devendo estar presente, de forma articulada, em todos os níveis e modalidades do processo educativo, em caráter formal e não formal" (BRASIL, 1999).

A Educação Ambiental representa um processo com potencial para promover transformação social, desde que realizada com esse compromisso. Para Layrargues (2009),

\begin{abstract}
Educação Ambiental com compromisso social é aquela que articula a discussão da relação entre o ser humano e a natureza inserida no contexto das relações sociais. É aquela que propicia o desenvolvimento de uma consciência ecológica no educando, mas que contextualiza seu projeto políticopedagógico de modo a enfrentar também a padronização cultural, exclusão social, concentração de renda, apatia política; além da degradação da natureza. É aquela que enfrenta o desafio da complexidade, incorporando na reflexão categorias de análise como trabalho, mercadoria e alienação.
\end{abstract}

A agroecologia, como tema norteador do debate em Educação Ambiental, é altamente relevante, visto que apresenta enorme potencial para transformar a realidade com compromisso social, uma vez que a produção de base agroecológica é considerada, conforme a Política Nacional de Agroecologia e Produção Orgânica:

aquela que busca otimizar a integração entre capacidade produtiva, uso e conservação da biodiversidade e dos demais recursos naturais, equilíbrio ecológico, eficiência econômica e justiça social [...] (BRASIL, 2012).

Segundo Altieri (2008), a produção sustentável em um agroecossistema deriva do equilíbrio entre plantas, solos, nutrientes, luz solar, umidade e outros organismos coexistentes. Ainda de acordo com esse autor, os elementos técnicos básicos de uma estratégia para produção agroecológica são conservação e regeneração dos recursos naturais (solo, água, germoplasma, fauna e flora benéficas) e manejo dos recursos produtivos (diversificação, reciclagem dos nutrientes e matéria orgânica, regulação biótica). A prática da 
agroecologia reduz os impactos ambientais promovidos pela agricultura convencional ou moderna, baseada na Revolução Verde, implementada no Brasil nas décadas de 60 e 70, caracterizada por pacotes tecnológicos que priorizam

- subsídio de créditos agrícolas para estimular a grande produção agrícola, as esferas agroindustriais, as empresas de maquinários e de insumos industriais para uso agrícola - como tratores, herbicidas e fertilizantes químicos - a agricultura de exportação, a produção de processados para a exportação e a diferenciação do consumo (MOREIRA, 2000).

A produção agrícola baseada na Revolução Verde, como mencionado anteriormente, ainda é o modelo hegemônico de exploração agrícola no Brasil e em grande parte do mundo. Esse modelo é predatório e acarreta diversos impactos ambientais negativos, a saber: perda da biodiversidade de fauna e flora; acidez aumentada, desertificação, alagamento, salinização, perda de fertilidade e erosão do solo; poluição do solo e corpos hídricos, esgotamento e desperdício de água; poluição do ar e, por fim, impactos à saúde humana, em função de contaminações de recursos naturais e de alimentos decorrentes das práticas agrícolas, bem como contaminações dos trabalhadores envolvidos nas atividades relacionadas a essa produção (MILLER; SPOOLMAN, 2015). De acordo com Leite e Torres (2008),

de todas as atividades humanas, a agricultura é a que ocupa as maiores áreas terrestres e uma das que mais provoca modificações no meio ambiente. Em muitos casos, os piores impactos causados por ela são invisíveis aos olhos da população, dos consumidores e dos próprios agricultores.

Sendo assim, o foco principal da agroecologia é "a manutenção da produtividade agrícola com o mínimo possível de impactos ambientais e com retornos econômico-financeiros adequados à meta de redução da pobreza, atendendo às necessidades sociais das populações rurais" (ALMEIDA, 2008).

Ademais, considerando todos os aspectos anteriormente abordados, cabe reforçar que, na promoção da Educação Ambiental, a agroecologia é um tema de extrema relevância que deve ser tratado tanto na educação formal quanto na educação não formal, para que os conhecimentos vinculados a essa ciência sejam amplamente difundidos e possam ser incorporados por agricultores e agricultoras, tanto na zona rural quanto na urbana, bem como por profissionais que atuam ou atuarão na assistência técnica a agricultores e agricultoras.

Pensar a educação formal para a população do campo tem sido um grande desafio histórico. O acesso aos direitos básicos, como educação 
gratuita e de qualidade é, sem dúvida, uma dívida com as comunidades rurais brasileiras. Segundo Silva (2018), essa falta de acesso à educação resulta de um processo multifatorial incluindo aspectos econômicos, sociais e culturais. A falta de políticas públicas adequadas resultou na precariedade do funcionamento da escola rural, que pode ser observada na infraestrutura inadequada, na má distribuição geográfica das escolas e na falta de condições de trabalho e de formação específica de profissionais para atuação no meio rural, ou seja, nos elementos humanos necessários para o trabalho pedagógico (SILVA, 2008). O movimento da Educação do Campo tem discutido essas questões e buscado formar profissionais que possam atender à população com uma educação contextualizada, dentro das múltiplas realidades do campo brasileiro (MOLINA; FREITAS, 2011). A indissociabilidade entre o ensino e a extensão é premissa básica para se pensar a atuação na formação escolar e profissional de agricultoras e agricultores. Cursos de ensino que sejam pensados a partir da problematização junto às comunidades rurais e que busquem atender a demandas locais para solução de problemas podem contribuir significativamente para a transformação das realidades locais e para superar o modelo inadequado de educação que desrespeita o modo de vida e a cultura da população do meio rural (SILVA, 2008; ANDRADE et al., 2017).

Nessa perspectiva, objetiva-se aqui relatar e analisar o processo de realização de um curso de Formação Inicial e Continuada (FIC) para Agricultor(a) Orgânico(a) e Agroecológico(a) que visou reunir agricultores(as), professores(as), estudantes, agentes de assistência técnica e extensão rural, assentados(as) de reforma agrária e representantes de comunidades tradicionais, a fim de que pudessem trocar saberes sobre diversas temáticas indicadas como prioritárias para promoção da sustentabilidade, buscando assim superar os desafios e identificar as potencialidades locais dentro da diversidade de realidades existentes no ambiente rural do Vale do Mucuri, Minas Gerais.

\section{Metodologia}

O território do Vale do Mucuri, no Nordeste de Minas Gerais, ocupa uma área de aproximadamente 23,2 mil km² e é constituído por 27 municípios, a saber: Águas Formosas, Ataléia, Bertópolis, Campanário, Caraí, Carlos Chagas, Catuji, Crisólita, Franciscópolis, Frei Gaspar, Fronteira dos Vales, Itaipé, Itambacuri, Ladainha, Machacalis, Malacacheta, Nanuque, Novo Oriente de Minas, Ouro Verde de Minas, Pavão, Pescador, Poté, Santa Helena de Minas, Serra dos Aimorés, Setubinha, Teófilo Otoni e Umburatiba (GEPAF, 2010).

A população do Vale do Mucuri é de 438.257 habitantes, segundo dados do Atlas do Desenvolvimento Humano referentes ao ano de 2010 (ATLAS, 2013), o que corresponde a $2,2 \%$ da população do estado de Minas Gerais. Nesse vale, $34,0 \%$ da população reside na zona rural, o que representa mais que o dobro do percentual médio de pessoas que habitam a zona rural no 
estado de Minas Gerais (14,7\%). Segundo o GEPAF (2010), os habitantes da zona rural do Vale do Mucuri "sofrem as trágicas consequências sócioecológicas e culturais do processo de modernização conservadora dos espaços rurais". Ainda conforme o GEPAF (2010),

por todo território observa-se intensa degradação dos solos, desmatamentos dos remanescentes da Mata Atlântica, queimadas e assoreamento de córregos e rios. As porções oeste e noroeste do Território, notadamente ocupadas pelas famílias agricultoras, apresentam as maiores áreas verdes. Desolador cenário é observado na região leste: imensas monoculturas de cana e pastagens, forte concentração de terra e renda, poucas comunidades rurais e elevado índice de desmatamentos. [...]

Para dar continuidade a sua reprodução sociocultural, a agricultura familiar tem como grande desafio a melhoria/manutenção da saúde ambiental de suas áreas. Nos sistemas agrícolas, a qualidade dos solos, água e ar são fatores determinantes e incidem diretamente na vida, produtividade e renda das famílias agricultoras.

Diante dessa realidade, no ano de 2016, o Grupo de Extensão e Pesquisa em Agricultura Familiar (GEPAF) da UFVJM e o IFNMG, Campus Teófilo Otoni, formaram o Núcleo Mucuri de Agroecologia com diversas instituições parceiras, dentre elas a Pastoral Rural da Diocese de Teófilo Otoni, a Rede de Ensino Doctum, a EMATER-MG, o Instituto Estadual de Florestas (IEF), a Prefeitura Municipal de Teófilo Otoni, o Centro Agroecológico Tamanduá (CAT), o Centro de Agricultura Alternativa Vicente Nica (CAV) e o Núcleo de Agroecologia de Governador Valadares (NAGÔ)/UFJF-GV. Esse Núcleo visa promover ações junto a agricultores e agricultoras familiares, assentados de reforma agrária e comunidades quilombolas que possam fortalecer a agroecologia no Vale do Mucuri. Dentre as ações executadas, o Núcleo Mucuri de Agroecologia construiu a proposta do curso de Formação Inicial e Continuada (FIC) para Agricultor(a) Orgânico(a) e Agroecológico(a) com os seguintes objetivos:

1. Promover um espaço de ensino-aprendizagem que possibilite a troca de conhecimentos entre os diversos atores envolvidos no curso: agricultores(as), técnicos(as), professores(as) e estudantes.

2. Capacitar agricultores e agricultoras no desenvolvimento de sistemas agrícolas de produção mais sustentáveis e adequados à realidade local.

3. Capacitar agricultores e agricultoras na aplicação de técnicas associadas à produção agrícola local para preservação e recuperação da qualidade dos solos e das águas. 
4. Capacitar agricultores e agricultoras na comercialização e certificação de produtos orgânicos e agroecológicos, de acordo com as políticas públicas existentes e com a legislação vigente.

5. Capacitar agentes de assistência técnica e extensão rural e estudantes do ensino básico, técnico e tecnológico para a atuação em atividades de extensão relacionadas à agricultura orgânica e agroecológica junto às comunidades rurais.

Os temas abordados no Curso FIC foram escolhidos a partir de visitas prévias às comunidades atendidas, quando pessoas das próprias comunidades sugeriram temas relevantes para a solução de problemas locais. Além disso, estudos e diagnósticos realizados anteriormente contribuíram para o levantamento de temas prioritários a serem trabalhados na região com a perspectiva de contribuir para a transição agroecológica nesse território, entendendo-se essa transição como um processo gradual de mudança de práticas e de manejo em agroecossistemas, incorporando princípios e tecnologias de base ecológica, a fim de transformar as bases produtivas e sociais do uso da terra e dos recursos naturais (GEPAF, 2010; BRASIL, 2012).

O curso, realizado nos anos de 2017 e 2018, foi dividido em sete módulos, sendo cada módulo realizado em, no mínimo, dois dias consecutivos, nos fins de semana, para facilitar a participação dos inscritos. Os módulos do curso foram oferecidos em comunidades rurais, em localidades diferentes, visando compreender os desafios e potencialidades locais dentro das diversas realidades existentes no Vale do Mucuri, além de buscar garantir maiores possibilidades de trocas de conhecimentos entre os inscritos e possibilitar também que outras pessoas das comunidades pudessem participar dos mesmos espaços de socialização de conhecimentos. Essa metodologia foi inspirada na metodologia dos intercâmbios agroecológicos, uma eficiente estratégia no processo de construção e socialização de conhecimentos agroecológicos na Zona da Mata mineira para o fortalecimento das dinâmicas sociais dos agricultores nessa região (ZANELLI; SILVA, 2017), e também considerou a perspectiva de Caporal (2013) de que a

agroecologia sustenta que o manejo dos agroecossistemas tem uma forte relação com os saberes e culturas locais. E é por isso que não podem existir receitas para a prática de agriculturas mais sustentáveis, pois as formas de produção serão tantas quantos forem os arranjos possíveis entre as culturas e os saberes dos agricultores(as) e as potencialidades e os limites naturais de cada agroecossistema, de cada território. 
O conhecimento local, desenvolvido e acumulado ao longo das gerações, é dinâmico, contextual e específico de uma determinada localidade (OUDWATER; MARTIN, 2003), de forma que as decisões sobre o uso da terra tomadas pela população local costumam ser mais precisas e adequadas do que as recomendações técnicas emitidas por especialistas externos (BARRERA-BASSOLS et al., 2006). Por isso, a orientação didático-pedagógica do curso fundamentou-se na metodologia freireana de educação de jovens e adultos e de extensão rural, partindo do saber dos educandos em ambientes de troca e construção de conhecimento (FREIRE, 1983). Nesse sentido, a proposta metodológica priorizou a construção coletiva de conhecimento, com a participação de professores(as), estudantes, técnicos(as) e agricultores(as) em contraposição ao difusionismo tecnológico que já se mostrou um método inadequado de ensino e extensão para o desenvolvimento rural. Partiu-se da concepção construtivista crítica de Paulo Freire que, segundo Gadotti (1997), vai além da pesquisa e da tematização e pressupõe a ação transformadora através da terceira etapa do seu método: a problematização. Assim, as ações de ensino e extensão tiveram como objetivo maior a transformação da realidade de agricultores e agricultoras, melhorando seus sistemas de produção a partir de seu próprio conhecimento, em diálogo com o conhecimento científico produzido nas instituições de ensino e pesquisa. Os temas abordados em cada módulo e os locais e as datas em que o Curso para Agricultor(a) Orgânico(a) e Agroecológico(a) foi realizado são apresentados na Tabela 1.

Tabela 1: Datas, temas e locais em que os módulos do Curso FIC foram realizados.

\begin{tabular}{|c|c|}
\hline Módulo e Data & Tema e local de realização \\
\hline 13 a $17 / 07 / 17$ & $\begin{array}{l}\text { Intercâmbio no Vale do Rio Doce para vivenciar as experiências de } \\
\text { agricultores(as) ligados ao Centro Agroecológico Tamanduá (CAT), em } \\
\text { Governador Valadares, e participação na X Troca de Saberes da } \\
\text { Universidade Federal de Viçosa }\end{array}$ \\
\hline 19 a $20 / 08 / 17$ & $\begin{array}{l}\text { Manejo e Conservação de Solo e Água - Assentamento Fritz, Teófilo } \\
\text { Otoni }\end{array}$ \\
\hline $\begin{array}{c}3 \\
28 \text { a } 29 / 10 / 17\end{array}$ & $\begin{array}{l}\text { Manejo Agroecológico de Pragas e Doenças - Comunidade Soledade, } \\
\text { Teófilo Otoni }\end{array}$ \\
\hline $\begin{array}{c}\mathbf{4} \\
24 \text { a } 26 / 11 / 17\end{array}$ & $\begin{array}{l}\text { Intercâmbio em Turmalina, região do Alto Vale do Jequitinhonha, para } \\
\text { troca de experiências com agricultores familiares e técnicos de ATER do } \\
\text { Centro de Agricultura Alternativa Vicente Nica (CAV) }\end{array}$ \\
\hline $\begin{array}{c}5 \\
27 \text { a } 28 / 01 / 18\end{array}$ & $\begin{array}{l}\text { Produção Animal em Sistemas Agroecológicos - Córrego do Cipó, Teófilo } \\
\text { Otoni }\end{array}$ \\
\hline $\begin{array}{c}6 \\
17 \text { a } 18 / 03 / 18\end{array}$ & $\begin{array}{l}\text { Políticas públicas para a agricultura familiar - Comunidade Quilombola } \\
\text { Santa Cruz, Ouro Verde de Minas }\end{array}$ \\
\hline $\begin{array}{l}7 \\
05 \text { a } 06 / 05 / 18\end{array}$ & Saneamento Rural - Comunidade Itamunheque, Teófilo Otoni \\
\hline
\end{tabular}

Fonte: Autoria própria. 
Os Módulos 1 e 4, supracitados, foram denominados "intercâmbio" por terem sido realizados fora do Vale do Mucuri, para os cursistas vivenciarem experiências de regiões diferentes; além disso, seguiram programação diferenciada, pois os locais e eventos foram bastante diversificados. A programação geral, que foi adotada nos outros módulos, também foi baseada na metodologia dos intercâmbios agroecológicos (ZANELLI; SILVA, 2017) e está apresentada na Tabela 2.

Tabela 2: Programação geral dos módulos do Curso FIC.

\begin{tabular}{ll}
\hline & Sábado \\
\hline $12: 00$ & Almoço \\
13:00 & Acolhida e mística de abertura \\
& Apresentação dos participantes, dos objetivos e da programação \\
$13: 30$ & Histórico da comunidade \\
$14: 00$ & Realização de Caminhada Transversal \\
$16: 00$ & Café \\
$16: 30$ & Exposição dialogada \\
$18: 00$ & Encerramento e encaminhamentos para o dia seguinte \\
19:00 & Jantar \\
\hline 19:30 & Programação cultural \\
\hline 7:00 & Domingo \\
8:00 & Café \\
9:20 & Trocio das atividades: divisão em grupos para as oficinas \\
11:00 & Avaliação e encerramento da atividade \\
$11: 30$ & Motivação para o próximo módulo \\
$12: 00$ & Almoço \\
\hline
\end{tabular}

Fonte: Autoria própria.

A proposta da metodologia utilizada em todos os módulos era, nos momentos iniciais, conhecer a realidade, os potenciais e os desafios da comunidade onde eram realizados, por meio de relato do seu histórico e da caminhada transversal, uma técnica que 
permite obter informação sobre os diversos componentes dos recursos naturais, a vida econômica, as moradias, as características de solos, etc. É realizada por meio de uma caminhada linear, que percorre um espaço geográfico com várias áreas de uso e recursos diferentes. Ao longo da caminhada se anotam todos os aspectos que surgem pela observação dos participantes em cada uma das diferentes zonas que se cruzam (VERDEJO, 2010).

Em seguida, era realizada uma exposição dialogada sobre o tema do módulo, considerando e buscando compreender a realidade observada para que depois fossem discutidas formas de superar os desafios encontrados e de aproveitar as potencialidades da comunidade. No segundo momento, eram realizadas oficinas (Tabela 3), que consistiam na socialização e realização de práticas agroecológicas como forma de colocar em ação as discussões realizadas anteriormente e de aplicar o conhecimento construído na resolução dos problemas da realidade local.

Tabela 3: Lista de oficinas realizadas durante os módulos do curso FIC.

\begin{tabular}{cl}
\hline Módulo & \multicolumn{1}{c}{ Oficina } \\
\hline 2 & $\begin{array}{l}\text { Marcação de curvas de nível com uso de nível de mangueira e nível pé de } \\
\text { galinha e construção de cordão de vegetação permanente e terraços } \\
\text { Construção de sistema agroflorestal }\end{array}$ \\
\hline 3 & $\begin{array}{l}\text { Preparação dos biofertilizantes EM (Microorganismos Eficazes) e Bokashi } \\
\text { Indicaçães de uso de plantas repelentes e preparação de armadilhas e caldas }\end{array}$ \\
\hline 5 & $\begin{array}{l}\text { Produção de ração alternativa } \\
\text { Preparação de produtos homeopáticos }\end{array}$ \\
\hline 6 & $\begin{array}{l}\text { Mulheres e agroecologia } \\
\text { Assistência técnica e extensão rural } \\
\text { Educação do campo e juventude }\end{array}$ \\
& $\begin{array}{l}\text { Territórios tradicionais } \\
\text { Terapias tradicionais e cultura }\end{array}$ \\
\hline 7 & Construção de fossa séptica biodigestora \\
Coleta de amostra de água, teste microbiológico e análise de resultados
\end{tabular}

$$
\text { Fonte: Autoria própria. }
$$

Ao final de cada módulo, foi reservado um momento para avaliação pelos cursistas e demais presentes. Além disso, ao final do curso, foram realizados dois momentos de avaliação geral: um ao final do último módulo e o outro no II Seminário de Agroecologia, quando também foi realizada a cerimônia de formatura dos cursistas.

\section{Resultados e discussão}

Participaram do curso sessenta e um inscritos de dez municípios diferentes do Vale do Mucuri e adjacências, entre eles, estudantes dos ensinos médio e superior, estudantes de escolas famílias agrícolas (EFAs), 
professores, técnicos de assistência técnica e extensão rural, agricultores(as) familiares, agricultores(as) de um assentamento de reforma agrária e de uma comunidade quilombola.

O primeiro módulo possibilitou a troca de experiências e conhecimentos entre os(as) agricultores(as) do Vale do Mucuri, do Vale do Rio Doce e da Zona da Mata Mineira. Nesse intercâmbio foi abordada a fundamentação teórica, a conceitual e a histórica da agroecologia. As atividades foram realizadas em parceria com o Centro Agroecológico Tamanduá (CAT) e o Núcleo de Agroecologia da UFJF de Governador Valadares (NAGÔ), quando se visitou a sede do CAT na cidade e as unidades produtivas familiares em Tumiritinga (MG) e lapu (MG). Na viagem ao Vale do Rio Doce, foi possível vivenciar e debater os desafios da agroecologia perante o impacto da mineração e de outros grandes empreendimentos depredatórios na segurança alimentar, na sobrevivência e na reprodução material e cultural das comunidades ribeirinhas a partir de uma visita a uma unidade produtiva familiar às margens do Rio Doce, atingida pelo rompimento da barragem de rejeitos de mineração de Fundão da VALE/SAMARCO/BHP. Além disso, os inscritos no curso participaram da Troca de Saberes da Universidade Federal de Viçosa (UFV) (MG). Este evento ocorre desde 2009 e se caracteriza por apresentar uma programação que objetiva a troca de conhecimentos tradicionais e científicos.

Os Módulos 2, 3, 5 e 7 foram realizados em comunidades rurais do município de Teófilo Otoni (MG), e o Módulo 6 foi feito em uma comunidade rural quilombola no município de Ouro Verde de Minas (MG). O Módulo 4, realizado em parceria com o Centro de Agricultura Alternativa Vicente Nica (CAV), localizado em Turmalina (MG), foi focado na socialização das experiências de comercialização e de certificação participativa de agricultores familiares e de técnicos em Assistência Técnica e Extensão Rural (ATER) do Vale do Jequitinhonha. Estão retratados, nas Figuras 1 e 2, momentos de interação entre os cursistas durante as práticas agroecológicas nas oficinas de construção de Sistema Agroflorestal (Módulo 2) e de Terapias Tradicionais e Cultura (Módulo 6), respectivamente.

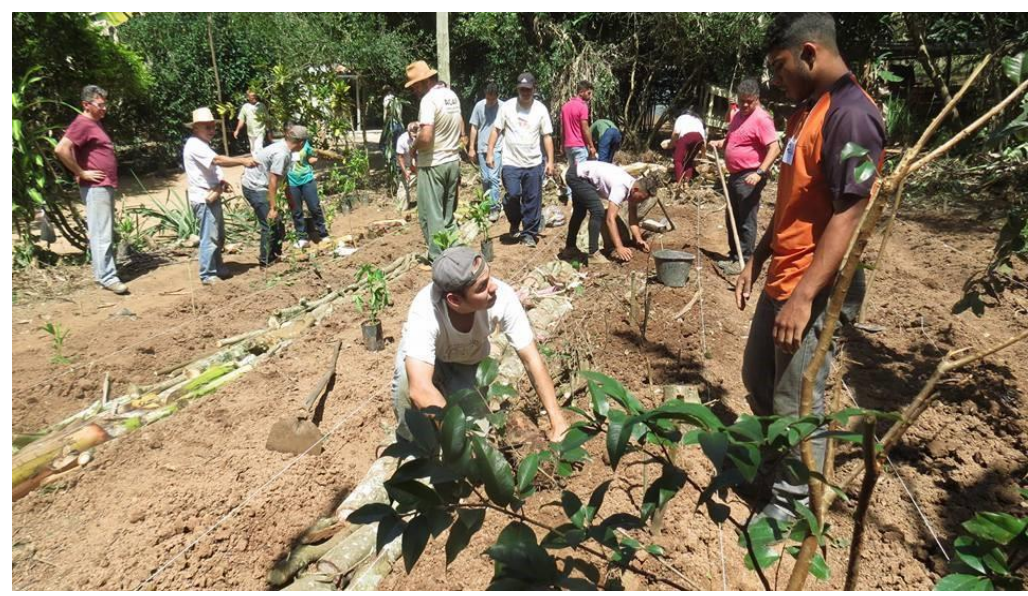

Figura 1: Oficina de construção de Sistema Agroflorestal. Fonte: Núcleo Mucuri de Agroecologia (2017).

Revbea, São Paulo, v.16, № 1: 359-377, 2021. 


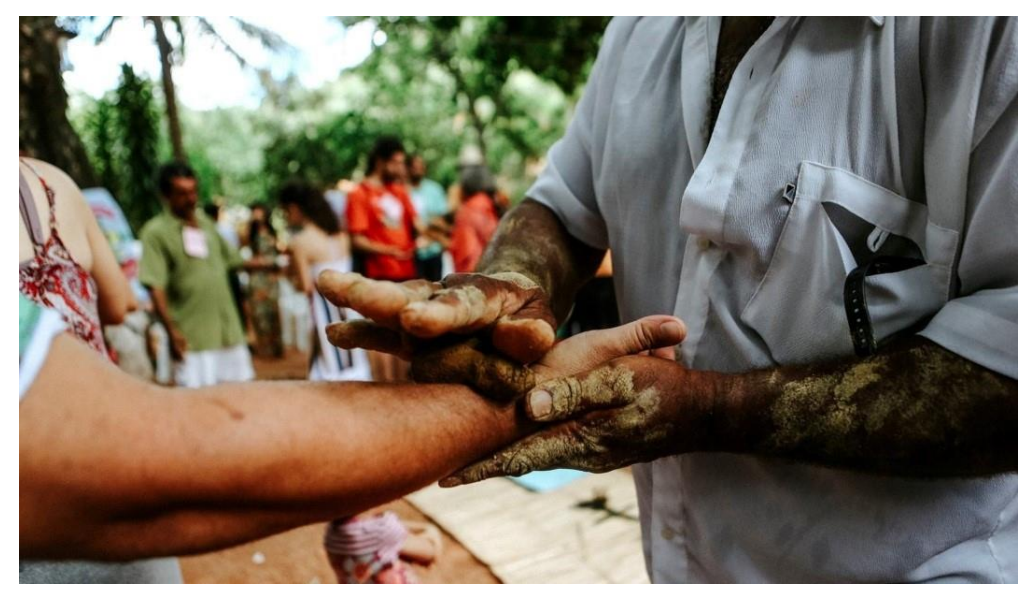

Figura 2: Prática realizada durante a oficina de Terapias Tradicionais e Cultura.

Fonte: Leonardo Cambuí (2018).

Momentos como esses possibilitaram a troca de conhecimentos entre os cursistas, que, tanto na exposição dialogada quanto nas oficinas, foram incentivados a se manifestarem, pois, conforme Freire (1987), "não é no silêncio que os homens se fazem, mas na palavra, no trabalho, na açãoreflexão". Além disso, as dinâmicas realizadas possibilitaram que agricultoras e agricultores despertassem sua voz ativa na condução do curso, enriquecendo os diálogos e a construção da prática agroecológica nas comunidades. Esse diálogo entre instituições de ensino e comunidade externa potencializa a conciliação entre saberes tradicionais e científicos, buscando colocá-los no mesmo patamar de importância. De certa forma, o depoimento a seguir mostra que a interação entre os saberes locais promovida pelo curso foi bem sucedida:

Participar desse curso... É... eu vejo como uma oportunidade muito proveitosa, né? Oportunidade de conhecer outras pessoas que pensam... É..., algo parecido com que a gente pensa, né? E... A gente achava que no Mucuri não existia agroecologia... Né? E foi bom, né? A intenção deste curso de começar a reunir pessoas que já praticam agroecologia no Vale do Mucuri, né? A gente começar a se organizar num movimento pra, num futuro próximo, a gente já começar a colher frutos, né? Do que foi aprendido aqui. É... Realmente, eu achei uma oportunidade muito enriquecedora e recomendo pra todos (AGRICULTOR 1).

Ademais, o Agricultor 1 demonstra desconhecimento da existência de práticas agroecológicas no Vale do Mucuri, percepção que foi alterada a partir da realização do curso, o que já é um excelente resultado, pois, por meio do conhecimento de práticas já existentes, os agricultores podem ficar motivados a replicá-las, cada um em sua unidade. Nesse sentido, é notório que a socialização das práticas de manejo do solo, da água, dos conhecimentos 
tradicionais de cada comunidade é fundamental para a construção de novos conhecimentos, que, ao longo do tempo, aprimoram-se cada vez mais e ganham força entre as localidades.

Além disso, as percepções relatadas pelo GEPAF (2010) e destacadas a seguir sobre os agricultores familiares do Vale do Mucuri foram evidenciadas durante 0 curso de forma bastante prática, por meio das caminhadas transversais e da socialização das práticas agrícolas nas comunidades.

A maioria dos/as agricultores/as do Mucuri não utiliza adubos químicos ou venenos, sendo notável a intensa diversificação produtiva para autoconsumo e comercialização. A multiplicidade de práticas agrícolas notadas nos sistemas familiares retrata as formas de viver, organizar e conhecer das populações identificadas com o campo. A riqueza de espécies nos quintais, locais de característico cuidado feminino, evidencia 0 importante papel das mulheres na conservação/ampliação da agrobiodiversidade e dos saberes associados aos usos das plantas. Saberes estes presentes aos sábados nos mercados municipais, onde as feiras saúdam os/as moradores/as das pequenas cidades com produtos alimentares, medicinais e ornamentais.

No depoimento do Agricultor 2, também é destacada a necessidade de organização da comunidade e a importância que o curso teve no sentido de contribuir para essa organização:

Esse projeto que tá sendo desenvolvido é importante pra nós porque leva a comunidade a se organizar, é um projeto que leva as pessoas a organizar, né? Cuidando da saúde, cuidando de si próprio mesmo, né? É um projeto que nós temos, né? Que veio enriquecer a nossa comunidade (AGRICULTOR 2).

O depoimento supracitado também mostra que ações que visam promover construção coletiva do conhecimento, como a proposta deste curso, têm significativo mérito, sobretudo, porque além de socializar conhecimentos durante a realização do curso, podem potencializar a busca de mais informação por parte dos participantes, além de possibilitar outras trocas entre participantes e não participantes, como pode ser percebido na fala de uma agricultora (AGRICULTORA 3), impulsionando a formação de redes muito importantes para o avanço da transição agroecológica:

[...] E a gente vai passar para os nossos filhos. Eu vou até passar um zap pra menina ali, pra Denise, pra Denise enviar pra meu filho o que nós aprendemos, para ele fazer lá na nossa comunidade também (AGRICULTORA 3). 
O fortalecimento dos laços entre as comunidades de agricultura familiar através da formação dessas redes em que agricultores e agricultoras assumem o protagonismo é de suma importância para o fortalecimento da agroecologia no Vale do Mucuri, e as instituições envolvidas na organização e realização do referido curso se afirmam também como atores fundamentais nesse processo.

Costabeber e Moyano Estrada (1998) tecem relevantes considerações sobre a importância da ação coletiva no processo de transição agroecológica, conforme destacado no trecho a seguir, o que parece ter ficado claro tanto para o Agricultor 1 quanto para o Agricultor 2.

Nosso argumento é que, se bem o começo da transição agroecológica dependa muito mais de ações isoladas de indivíduos com atitudes favoráveis ao câmbio, sua consolidação como processo de ecologização gera, paralelamente, novos desafios e incertezas sobre suas consequências e resultados futuros, originando, a partir disso, a necessidade e a pertinência de abordar-se de forma coletiva os novos desafios que se estabelecem. A ação coletiva e as estratégias associativas não são apenas resultados deste processo, mas incidem e afetam o seu desenvolvimento e evolução. As ações sociais coletivas são, pois, ao mesmo tempo, o resultado e a causa do processo de transição em direção a conformação de estilos de agricultura de base ecológica (COSTABEBER; MOYANO ESTRADA, 1998).

Outra questão importante pode ser observada a partir do depoimento do Agricultor 2, que revela compreensão referente à relação entre agroecologia e saúde. Em diversos momentos das narrativas dos participantes ao longo do curso, essa relação foi destacada, o que demonstrou efetividade na compreensão desse aspecto pelo coletivo. Uma vez potencializados o aumento de renda e a melhoria da saúde desses muitos agricultores, outro ganho esperado é o aumento do Índice de Desenvolvimento Humano Municipal (IDHM) de seus municípios de residência, o que seria muito importante no contexto do Vale do Mucuri, visto que dois deles estão entre os 10 municípios que apresentam os menores índices de IDHM de Minas Gerais (estado que possui 853 municípios) e seis municípios possuem índices de IDHM que os classificam entre os 100 menores valores de Minas Gerais, a saber: Setubinha

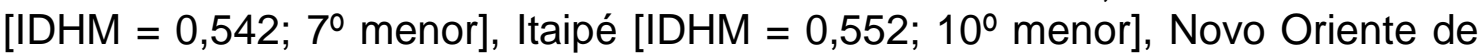
Minas [IDHM $=0,555 ; 12^{\circ}$ menor], Crisólita [IDHM $=0,585 ; 46^{\circ}$ menor], Bertópolis [IDHM =0,594; $61^{\circ}$ menor] e Ouro Verde de Minas [IDHM = 0,595; 64ํㅡㄹ menor] (ATLAS, 2013).

A importância da agroecologia para a promoção da segurança e da soberania alimentar das comunidades rurais foi amplamente debatida ao longo do curso. De acordo com o Ex-Relator Especial das Nações Unidas para o 
Direito à Alimentação, Jean Ziegler, alimentos seguros e saudáveis contribuem para uma vida digna e plena tanto física quanto mentalmente, conforme destacado a seguir:

O direito à alimentação adequada é um direito humano inerente a todas as pessoas de ter acesso regular, permanente e irrestrito, quer diretamente ou por meio de aquisições financeiras, a alimentos seguros e saudáveis, em quantidade e qualidade adequadas e suficientes, correspondentes às tradições culturais do seu povo e que garanta uma vida livre do medo, digna e plena nas dimensões física e mental, individual e coletiva (ABRANDH et al. , 2009).

Em relação à avaliação do curso, este foi bem avaliado pelos participantes, que destacaram pontos positivos referentes à estrutura, à metodologia e ao conteúdo, conforme descrito a seguir:

Estrutura: gratuidade do curso e da estadia, visto que as estruturas de alojamento foram cedidas pelos parceiros e pelas comunidades; preparação da alimentação como contrapartida das comunidades; locais de realização dos módulos bem escolhidos, com experiências enriquecedoras, contribuindo amplamente com a formação dos cursistas; datas e horários dos módulos organizados de forma coletiva e considerando-se a realidade dos cursistas, o que facilitou a vinda de quem morava mais distante do local de realização.

Metodologia e conteúdo: ambos foram dinâmicos e inclusivos e valorizaram os saberes dos agricultores; a metodologia contou com aulas práticas, o que facilitou a aprendizagem; os conteúdos foram relevantes e de extrema importância na formação dos cursistas.

Durante o II Seminário de Agroecologia, os cursistas apresentaram, de forma oral e em grupos, uma síntese dos conhecimentos adquiridos e das reflexões possibilitadas por meio do curso. Para a apresentação desta síntese, os cursistas utilizaram slides, cartazes, vídeos e textos produzidos por eles. Um dos grupos optou pela produção de poemas, um deles, transcrito a seguir:

Poesia da agroecologia

Autor: Romilson Ramos Cordeiro

Desde o início tudo mudou,

O meio ambiente já se transformou,

Tampamos nossos olhos para não ver,

Tudo está acontecendo e não queremos perceber.

Animais famintos, outros extintos.

As florestas mudaram,

Muitas árvores derrubaram. 
O povo consumista, não quer saber.

Pois a natureza pede ajuda,

Sem ninguém pra socorrer.

Foi então que surgiu um grupo no Vale do Mucuri, Buscando mudanças, para novas vidas surgir, Plantamos de tudo um pouco, fazendo multiplicação, Porque agroecologia é diversificação.

A agroecologia é um jeito novo de se viver, Empregando novas tecnologias, Mas valorizando a cultura e o saber.

Nossa produção é assim, diversificada, bem cuidada.

Que se possa tocar, com o pé, com a mão!

Que se possa comer, que se possa beber, sem intoxicação.

Nem na comida, nem na medicação!

No chá, natural, use hortelã, alecrim, manjericão.

Agroecologia é poesia, agronegócio é devastação.

Para fazer troca de experiências, fizemos várias viagens, Fomos para Turmalina conhecer o CAV, Conhecemos uma produção orgânica, sem a utilização de defensivos, Um modelo de agricultura a ser seguido.

Não poderia esquecer da troca de saberes, Tinha gente de todo lado, teve música, dança até mesmo uns gingados,

Capoeira é cultura de um povo que já foi escravizado.

A agricultura moderna visa só a produção,

Cultivando em grande escala, sem respeitar o chão,

Por isso te apresento a agroecologia,

Que respeita as diferenças em uma total sinergia.

Fazer parte deste grupo foi muito mais que bão, Aprendi várias coisas, mas a principal foi a união, Pena que o curso acabou, mas deixo aqui o meu recado, Lá na EFASET, ele vai estar sendo multiplicado.

Nesse poema, vários aspectos relacionados à agroecologia estão, de fato, presentes, a saber: impactos ambientais causados pelas ações humanas por meio da agricultura convencional; relação agroecologia/saúde; valorização dos conhecimentos tradicionais dos agricultores e das trocas de saberes; importância do coletivo nos processos agroecológicos; relação agroecologia/diversificação e, por fim, multiplicação dos conhecimentos construídos. A promoção de espaços para a discussão dos temas tratados neste curso é extremamente relevante quando se considera colocar em prática 
a Educação Ambiental com compromisso social, visando contribuir para uma melhor relação homem-natureza-sociedade, principalmente em uma região como o Vale do Mucuri, onde parcela significativa da população habita na zona rural e retira grande parte de sua renda da agricultura familiar. Quanto mais sustentável for a relação entre esses agricultores e os recursos naturais, maior qualidade de vida terão tais agricultores.

\section{Conclusões}

Com base nos depoimentos dos participantes e em seus relatos e posicionamentos durante os momentos de avaliação do curso para Agricultor(a) Orgânico(a) e Agroecológico(a), entende-se que os objetivos almejados no curso foram alcançados no que diz respeito à capacitação de agricultores e agricultoras, estudantes e agentes de Assistência Técnica e Extensão Rural em relação à aplicação de técnicas de preservação e recuperação da qualidade dos solos e das águas, associadas à produção agrícola local; ao manejo agroecológico de pragas e doenças; à produção animal em sistemas agroecológicos; às políticas públicas relacionadas à agricultura familiar e ao saneamento rural.

Considerando-se ainda os depoimentos dos participantes e seus relatos e posicionamentos durante os momentos de avaliação do curso, constatou-se que os cursistas têm ciência dos impactos ambientais causados pela agricultura convencional; da relação agroecologia/saúde; da valorização dos conhecimentos tradicionais dos agricultores e das trocas de saberes; da importância do coletivo nos processos agroecológicos e, por fim, da relação agroecologia/diversificação de culturas. Acredita-se que este curso contribuiu para que tais conhecimentos fossem construídos e/ou solidificados.

A metodologia utilizada, baseada em experiências locais, possibilitou a troca de conhecimentos entre os diversos atores envolvidos no curso: agricultores(as), professores(as) e estudantes, sendo criado um ambiente adequado e inovador para a construção de conhecimento agroecológico, colocando em prática a indissociabilidade entre ensino e extensão. A construção de parcerias foi fundamental para a realização das atividades e as comunidades colaboraram significativamente com a infraestrutura necessária ao desenvolvimento dos módulos. Tal metodologia contribuiu para dar visibilidade às práticas agroecológicas já desenvolvidas no Vale do Mucuri, antes desconhecidas por muitos participantes.

Por fim, o curso foi bem avaliado pelos participantes, destacando-se pontos positivos referentes à estrutura, à metodologia e ao conteúdo. Considerando todo o exposto, conclui-se que o curso para Agricultor(a) Orgânico(a) e Agroecológico(a), contribuiu para a construção do conhecimento agroecológico e para a formação de agentes multiplicadores, visando ao desenvolvimento de sistemas agroalimentares mais saudáveis, sustentáveis e adequados à realidade do Vale do Mucuri. 


\section{Agradecimentos}

Agradecemos, pelo apoio financeiro, à Secretaria de Estado de Desenvolvimento Agrário (SEDA) de Minas Gerais, à Fundação de Amparo à Pesquisa do Estado de Minas Gerais (FAPEMIG) - Processo AUC-00047-16, à Pró-Reitoria de Extensão e Cultura (PROEXC) da UFVJM, ao Programa Institucional de Bolsas Extensão para Discente (PIBED) do IFNMG e ao Conselho Nacional de Desenvolvimento Científico e Tecnológico (CNPq) Processo 403053/2017-0;

Agradecemos, ainda, às Associações e Comunidades de Agricultores(as) Familiares do Vale do Mucuri e adjacências, bem como aos demais membros e instituições que compõem o Núcleo Mucuri de Agroecologia, por todo o suporte dado à realização deste curso.

\section{Referências}

ABRANDH; CERESAN; CONSEA; FAO-RLC/ALCSH. Avanços e Desafios da Implementação do Direito Humano à Alimentação Adequada no Brasil. Relatório Técnico. Brasília, Rio de Janeiro: ABRANDH; CERESAN; CONSEA; FAO-RLC/ ALCSH, 2009. Disponível em <http://www.sesc.com.br/mesabrasil/doc/Avan\%C3\%A7os-e-desafios.pdf> Acesso em: 15 jan. 2020.

ALMEIDA, J. Apresentação à quinta edição. In: ALTIERI, M. Agroecologia: a dinâmica produtiva da agricultura sustentável. $5^{\underline{a}}$ ed. Porto Alegre: Editora da UFRGS, 2008. Disponível em <https://www.socla.co/wpcontent/uploads/2014/Agroecologia-Altieri-Portugues.pdf> Acesso em: 15 jan. 2020.

ALTIERI, M. Agroecologia: a dinâmica produtiva da agricultura sustentável. $5^{\text {a }}$ ed. Porto Alegre: Editora da UFRGS, 2008. Disponível em $<$ https://www.socla.co/wp-content/uploads/2014/Agroecologia-Altieri-

Portugues.pdf> Acesso em: 15 jan. 2020.

ASSIS, R. L. de. Desenvolvimento rural sustentável no Brasil: perspectivas a partir da integração de ações públicas e privadas com base na agroecologia. Revista Economia Aplicada, v. 10, n. 1, p. 75-89, jan-mar 2006.

ATLAS do Desenvolvimento Humano no Brasil Atlas dos Municípios: dados Município, Estado, País, 2013. Disponível em <http://www.atlasbrasil.org.br/2013/> Acesso em: 15 jan. 2020.

BARRERA-BASSOLS, N.; ZINK, J. A. \& VAN RANST, E. Local soil classification and comparison of indigenous and technical soil maps in a Mesoamerica community using spatial analysis. Geoderma (2006), pp. 140162.

BRASIL. Lei $\mathbf{N}^{\circ}$ 9.795, de 27 de abril de 1999. Disponível em <http://www.planalto.gov.br/ccivil 03/leis/19795.htm> Acesso em: 15 jan. 2020. 
BRASIL. Lei № 11.326, de 24 de julho de 2006. Disponível em <http://www.planalto.gov.br/ccivil 03/ Ato2004-2006/2006/Lei/L11326.htm>

Acesso em: 15 jan. 2020.

BRASIL. Decreto № 7.794, de 20 de agosto de 2012. Disponível em <http://www.planalto.gov.br/ccivil 03/ Ato2011-2014/2012/Decreto/D7794.htm> Acesso em: 15 jan. 2020.

CAPORAL, F. Aprendendo, fazendo conhecendo. Revista Agriculturas, v. 10, n. 3, p. 4-6, 2013.

CASTRO, C. N. Desafios da agricultura familiar: o caso da assistência técnica e extensão rural. Boletim Regional, Urbano e Ambiental do IPEA, n. 12, p. 4959, jul-dez. $2015 . \quad$ Disponível em $<$ http://repositorio.ipea.gov.br/bitstream/11058/6492/1/BRU n12 Desafios.pdf> Acesso em: 15 jan. 2020.

COSTABEBER, J. A.; MOYANO ESTRADA, E. Transição Agroecológica e Ação Social Coletiva (versão simplificada do Capítulo V da Tese de Doutorado do primeiro autor), 1998. Disponível em <http://coral.ufsm.br/desenvolvimentorural/textos/28.pdf> Acesso: 15 jan. 2020.

FREIRE, P. Pedagogia do Oprimido. $17^{\mathrm{a}}$ ed. Rio de Janeiro: Paz e Terra, 1987.

FREIRE, P. Extensão ou comunicação? $8^{\underline{a}}$ ed. Rio de Janeiro: Paz e Terra, 1983.

GADOTTI, M. Lições de Freire. Revista da Faculdade de Educação. v. 23 n. 1-2, 1997.

GEPAF. Atualização do plano de desenvolvimento territorial rural sustentável: território da cidadania Vale do Mucuri-MG. Universidade Federal dos Vales do Jequitinhonha e Mucuri. Pró-Reitoria de Extensão. Grupo de Pesquisa em Agricultura Familiar. Teófilo Otoni: UFVJM, 2010. 120 p. Disponível $\mathrm{em}$ $<$ http://sit.mda.gov.br/download/ptdrs/ptdrs qua territorio099.pdf> Acesso em: 15 jan. 2020.

IBGE. Censo demográfico 2010: características da população e dos domicílios - resultados do universo, 2011. Disponível em $<$ https://biblioteca.ibge.gov.br/visualizacao/periodicos/93/cd 2010 caracteristic as populacao domicilios.pdf> Acesso em: 15 jan. 2020.

IBGE, Censo agropecuário 2017, v. 8, p.1-105, 2019. Disponível em $<$ https://biblioteca.ibge.gov.br/visualizacao/periodicos/3096/agro 2017 resultad os definitivos.pdf> Acesso em: 15 jan. 2020.

LAYRARGUES, P. P. Educação Ambiental com compromisso social: o desafio da superação das desigualdades. In: LOUREIRO, C. F. B.; LAYRARGUES, P. P.; CASTRO, R. S. (Org.). Repensar a Educação Ambiental: um olhar crítico. São Paulo: Cortez, 2009. p. 11-31. 
LEITE, C. K.; TORRES, R. B. M. O uso de agrotóxicos pelos trabalhadores rurais do assentamento catingueira Baraúna (RN). Revista Verde, v. 3, n. 4, p. 06-28, out-dez 2008.

MILLER, G. T.; SPOOLMAN, S. E. Ciência Ambiental. 14a Ed. São Paulo: CENGAGE Learning, 2015.

MOLINA, M. C.; FREITAS, H. C. de A. Avanços e desafios na construção da educação do campo. Em Aberto, Brasília, v. 24, n. 85, p. 17-31, 2011.

MOREIRA, R. J. Críticas ambientalistas à Revolução Verde. Revista Estudos Sociedade e Agricultura, v. 15, p. 39-52, out. 2000.

OUDWATER, N.; MARTIN, A. Methods and issues in exploring local knowledge of soils. Geoderma 111 pp. 387-401. 2003.

SILVA, L. H. Educação do Campo e pedagogia da alternância. A experiência brasileira. Sísifo Revista de ciências da educação. n . 5 p. 105-112, 2008.

VERDEJO, M. E. Diagnóstico rural participativo: guia prático DRP. Brasília: MDA/Secretaria da Agricultura Familiar, 2010. Disponível em $<$ https://edisciplinas.usp.br/pluginfile.php/4616813/mod resource/intro/pageflip2583697-3759191-DRP - Guia prtico-2649689.pdf> Acesso em: 15 jan. 2020.

ZANELLI, F. V.; SILVA, L. H. Intercâmbios agroecológicos: processos e práticas de construção da agroecologia e da Educação do Campo na zona da mata mineira. PERSPECTIVA, Florianópolis, v. 35, n. 2, p. 638-657, abr./jun. 2017. 